\title{
The origins of open heart surgery at the University of Minnesota 1951 to 1956
}

\author{
Richard A. DeWall, MD
}

As a senior medical student in May 1951, I recall the excitement in the surgery department when Dr Clarence Dennis, who later became Chairman at Downstate University in New York, and his staff were in an operating suite to repair an atrial septal defect in a child by using open heart surgical techniques. They were using a heart-lung machine of the team's design; later, a second procedure was performed, but neither effort was successful.

In September 1952, approximately 1 year before the Minnesota cross-circulation experiments were initiated, Dr F. John Lewis made his mark in the surgical world with the first successful open heart procedure for the direct closure of an atrial septal defect. This was accomplished by reducing a patient's body temperature 10 degrees below normal. At this temperature, the patient's circulation could be stopped for up to 15 minutes, which fully protected the brain and was enough time for the direct repair of an atrial septal defect.

The patient's body temperature was reduced by immersion into a tub of ice water contained in a watering tank as used on a horse farm. A horse watering tank seemed an unlikely addition to a modern operating room. Dr C. Walton Lillehei assisted Dr Lewis with his hypothermia operations. The closure of an atrial septal defect was made through the atrial wall. Intraventricular defects required a ventriculotomy. A cold ventricle will fibrillate when incised. Converting the heart back to a normal sinus rhythm after closure of the ventricular incision while cold was difficult, leading Dr Lillehei to seek a method that would allow a transventricular approach in a warm heart.

Dr Norman Shumway, who later became director of the cardiothoracic program at Stanford University, served as the director of Dr Lewis's laboratory, which was adjacent to that of Dr Lillehei. Dr Lewis later joined the staff at Northwestern University.

Camaraderie prevailed throughout the department. Dr Shumway frequently visited Dr Lillehei's laboratory to keep up to date with our experiments, and we would check into Dr Lewis's laboratory to follow Dr Shumway's work with cardiac hypothermia.

After completing a military internship in New York, I returned to Minnesota in 1953. My interest was to work

From the Wright State University, Dayton, Ohio.

Address for reprints: Richard A. DeWall, MD, Wright State University Medical

School, 421 Thornhill Rd, Dayton, OH 45419 (E-mail: radewall@gmail.com).

J Thorac Cardiovasc Surg 2011;142:267-9

$0022-5223 / \$ 36.00$

Copyright (C) 2011 by The American Association for Thoracic Surgery doi:10.1016/j.jtcvs.2011.04.021 in laboratory medicine. I returned to my medical school to seek the advice of Dr Richard Varco, one of my surgery professors when I was a student. Dr Varco's secretary told me Dr Varco was in the operating room, and he would see me when he finished. As was customary at that time, I walked into the operating suite in street clothes to wait until Dr Varco finished his case. Scrub clothes, cap, and mask were required only within the actual operating room.

Dr Varco met me outside the operating suite. I mentioned to him my interest in laboratory medicine, similar to that of Dr Dennis. I showed him a plaster of Paris mock-up of a bileaflet valve that I made and envisioned could be developed into a prosthetic mitral valve. Dr Varco was receptive to my ideas, and he arranged for me to meet Dr C. Walton Lillehei. Dr Lillehei, whose interest was in the development of open heart surgery, introduced me to the director of his laboratory, Dr Herbert Warden, who later became chief of cardiothoracic surgery at the University of West Virginia.

Dr Morley Cohen, who later became chief of cardiothoracic surgery at the University of Manitoba in Winnipeg, preceded Dr Warden as director of Dr Lillehei's animal laboratory. During this transition in Dr Lillehei's laboratory, the two discussed the possibilities of open heart surgery. Dr Cohen's wife was pregnant at the time, and the thought of the fetus being supported by blood from the womb of a mother prompted discussion of using a donor dog as an oxygenator to support a recipient dog.

I began work with Dr Warden in March 1954. To test the concept of a donor being the oxygenator in a cardiac bypass system to permit open heart surgery, Dr Warden and I placed the patient dog and the donor dog on respective tables. We performed the proper arterial and venous cannulations and then opened the patient dog's chest for a sham open heart operation. The dog's arterial and venous cannulas were connected by plastic tubes running through a standard laboratory pump that controlled a balanced arterial and venous flow of blood between the donor and the recipient animals. Because I had no surgical experience, Dr Warden performed the surgery while I operated the pump. The procedure was called "controlled cross-circulation."

After many dozens of these sham procedures in dogs, Drs Warden, Cohen, and Lillehei were confident in taking the procedure into clinical application. Because I had the experience in managing the pump during the laboratory experiments, I was designated as the clinical perfusionist.

The clinical application of controlled cross-circulation was controversial because of an ethical conflict involving a surgical procedure on a normal donor. Permission to 
proceed with the surgery had to be reviewed and approved by the surgical department chairman, Dr Owen Wagensteen. After a proper review, Dr Wagensteen wrote a note to Dr Lillehei, "by all means go ahead, OHW." Dr Wagensteen was revered and respected by all for the educational programs he developed and the opportunities he provided for this entire staff.

The first clinical operation using cross-circulation was in March 1954. While walking back to the recovery room after a cross-circulation procedure, Dr Lillehei and I discussed the desirability of replacing the donor of the controlled cross-circulation with an artificial oxygenator. I became director of Dr Lillehei's laboratory while Dr Warden returned to his clinical activities. Attempts to build an oxygenator had been tried before by Drs John Gibbons, Clarence Dennis, and others. No pump-oxygenator system at that time proved to be generally acceptable.

Dr Lillehei mentioned that work on a mechanical blood oxygenator would be a good research project if I would be interested. I agreed that I would like to take on the project. He gave me 2 admonitions: (1) Avoid bubble systems, because they had such a bad record for perfusion support, and (2) do not do a literature search so as to avoid a prejudice toward one system or another. I worked with this objective in mind and began my research on the oxygenator project in the afternoons and evenings after manning the pump for the cross-circulation surgery in the mornings.

Dr Lillehei suggested that for the oxygenator design I might find use for a polyvinyl hose similar to that used in the food industry. The company of a friend of Dr Lillehei's produced such a hose. The suggested use of polyvinyl was fortuitous because glass as used in other oxygenator systems and known to activate thromboplastin, destroying the clotting mechanism of blood. Polyvinyl is blood compatible.

After 6 months of research, including several unsuccessful failed attempts at differing oxygenator systems, the helical reservoir bubble oxygenator proved successful. The same laboratory pump as used with cross-circulation procedures served with the helical bubble oxygenator to complete a successful heart-lung machine (Figure 1). The helical reservoir bubble oxygenator soon achieved wide application because it cost less than $\$ 20$ to construct, could be autoclaved, was used once, and discarded. The Gibbon vertical screen pump oxygenator designed by Dr Gibbon in Philadelphia was a large unit $\left(\sim 3^{\prime} \times 4^{\prime} \times 4^{\prime}\right)$ made of stainless steel, cost many thousands of dollars, and was difficult to clean and sterilize for reuse.

In May 1955, after many sham animal operations and 6 months of work with my research on the helical reservoir oxygenator, I was confident that the system would work. Dr Lillehei then proceeded with a successful open heart surgery operation in an infant using the helical reservoir oxygenator system (DeWall oxygenator). Hundreds of cases were to follow.

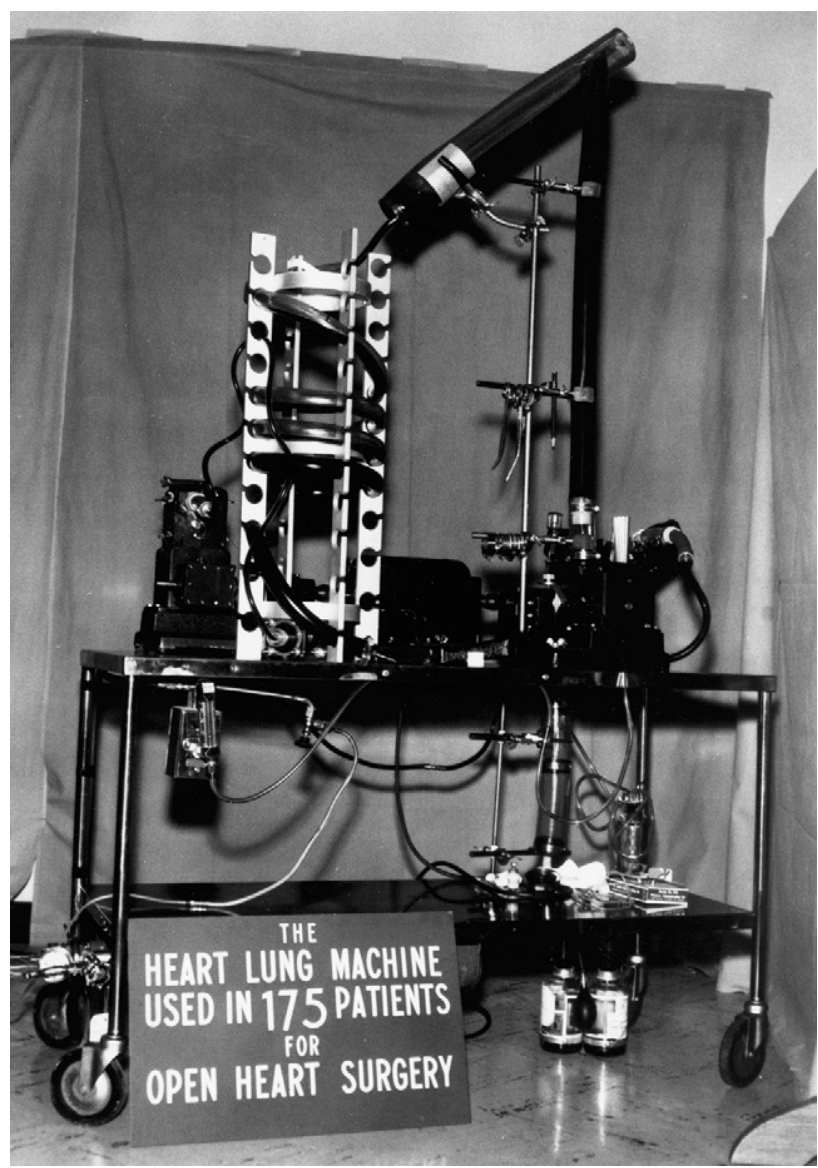

FIGURE 1. Helical reservoir pump oxygenator, 1955.

In 1954, Dr John Kirklin's team at the Mayo Clinic developed their own open heart surgical program. Their first open heart surgical procedure in March 1955 used their version of the Gibbon's pump-oxygenator (the Mayo-Gibbon oxygenator). A free exchange developed between the teams of Dr Kirklin and Dr Lillehei about their increasing experience in open heart surgery. Members from the Minneapolis team visited the Mayo Clinic, as did Mayo Clinic personnel visit the University of Minnesota's open heart surgery program. World-renowned cardiac surgeons visited Dr Lillehei's service and made the trip 90 miles south to the Mayo Clinic. It was a great thrill for me to meet these famous surgeons to show them all we had developed for perfusion and open heart surgery. In 1955, the open heart surgical programs at Minneapolis and Rochester Minnesota were the only places in the world where open heart surgery was performed on a regular basis.

Other interesting cardiac surgical problems were investigated at Minnesota simultaneously with the oxygenator. Dr Wangensteen's general surgical laboratory was adjacent to that of Drs Lewis and Lillehei. His laboratory director was Dr Earl Yonehiro. Earl, a Japanese American, served as a sniper sharpshooter in Italy during World War II. Dr Yonehiro's interest included cardiovascular subjects. 
In 1955, he initiated surgical experiments on the anastomosis of the left internal mammary artery to the left anterior descending coronary artery in dogs. He was ahead of the time in coronary artery surgery.

Surgically induced heart block presented a problem with some of the earlier ventricular septal defect repairs because intracardiac conduction anatomy was not well understood at that time. Dr Wagensteen conducted a surgical morbidity and mortality seminar every Saturday. All residents and surgical staff were expected to attend. Surgically induced complete heart block was discussed at several successive meetings. Dr Jack Johnson, a member of the physiology department, regularly attended the seminar. After a discussion during one session on heart block, Dr Johnson mentioned the application of a Grass Simulator, as used in physiology classes, to stimulate and study contraction of a frog's leg muscles. The Grass Stimulator produced a small voltage electrical charge. Dr Johnson suggested that such a charge would be an effective way to stimulate a patient's heart in complete heart block.

A couple of days later, Drs Vincent Gott and William Weirich went to the animal laboratory and set up an experimental heart block preparation. By using the Grass Stimulator, as suggested by Dr Johnson, they implanted an electrical wire into the dog's heart muscle and applied the stimulator. They were able to control the heart block as predicted.

In January 1957, a complete heart block developed in a child with a ventricular septal defect after a repair by Dr Lillehei. Dr Lillehei sent for Drs Gott and Weirich and the Grass Stimulator. Dr Lillehei inserted an insulated wire into the heart muscle of the patient and connected it to the stimulator. The procedure worked and controlled the total heart block.

The Grass Stimulator was about the size of a portable typewriter and required an AC outlet. A 100-foot extension cord was necessary to move the patient from the operating room to the recovery room. Dr Lillehei asked Earl Bakken, an electrical engineer who assisted the surgical department as an electronics consultant, to miniaturize the Grass Stimulator system. In April 1958, after approximately
2 weeks, Earl Bakken returned with a stimulator 2 times the size of a pack of playing cards. It served the pacemaker purpose well and was the start of the Medtronic Company (Minneapolis, Minn).

I never applied for a surgical residency in Dr Wagensteen's department of surgery, but after 2.5 years in research I was assigned to the clinical services. Dr Vincent Gott was my replacement in Dr Lillehei's laboratory to continue the work on oxygenator systems. He worked with prosthetic heart valves and later became chief of cardiothoracic surgery at Johns Hopkins University.

In the mid-1950s, Dr Christian Barnard joined Dr Wagensteen's group of residents. Early on, he showed interest in the open heart surgery program. Dr Barnard later served on Dr Lillehei's heart surgery service. Dr Barnard was offered an opportunity to stay on at the University of Minnesota, but he elected to return to his academic home, the University of Cape Town in South Africa, where he directed their heart surgery program. The first clinical heart transplant was performed there.

Dr Aldo Castenada became attached to Dr Lillehei's surgical program shortly after my time in the laboratory. Sometime later, Dr Castenada became the chief of cardiovascular surgery at Boston Children's Hospital.

In 1962, I was offered the opportunity to become Chairman of Surgery at the Chicago Medical School and moved to Chicago. Subsequently, I moved to Kettering Hospital in Dayton Ohio and Wright State Medical School.

There were many talented heart surgeons who graduated from Dr Lillehei's residency program and developed reputable heart surgery programs around the world..$^{1-3}$

I extend my appreciation to Dr Sylvan Weinberg for the generous help in editing this article.

\section{References}

1. Cooper DC. Open heart. New York: Kaplan Publishing; 2010.

2. Stoney WS. Pioneers of cardiac surgery. Nashville, TN: Vanderbilt University Press; 2008.

3. Schumacker HB Jr. The evolution of cardiac surgery. Bloomington, IN: Indiana University Press; 1992. 